\title{
Prevalence of congenital microcephaly and its risk factors in an area at risk of Zika outbreaks
}

Songying Shen ${ }^{1,2+}$, Wanqing Xiao ${ }^{1,2 \dagger}$, Lifang Zhang ${ }^{1,2+}$, Jinhua Lu ${ }^{1,2}$, Anna Funk ${ }^{3,4}$, Jianrong He ${ }^{1,2}, \mathrm{Si}_{\mathrm{Tu}}^{1,2}$, Jia Yu ${ }^{2}$, Li Yang ${ }^{2}$, Arnaud Fontanet ${ }^{4}$, Wei Bao ${ }^{5}$, Kar Keung Cheng ${ }^{6}$ and Xiu Qiu ${ }^{1,2,7^{*}}$ (D)

\begin{abstract}
Background: Prevalence of neonatal microcephaly in populations without Zika-epidemics is sparse. The study aimed to report baseline prevalence of congenital microcephaly and its relationship with prenatal factors in an area at risk of Zika outbreak.

Methods: This study included singletons born after 24 gestational weeks in 2017-2018 at four hospitals in Guangzhou, China. Microcephaly was defined as a head circumference at birth >3SD below the mean for sex and gestational age. Prevalence of microcephaly was estimated by binomial exact method. Multivariable logistic regression was used to examine the associations of microcephaly with prenatal factors. The population attributable fraction (PAF) for associated risk factors was calculated.

Results: Of 46,610 live births included, 154 (3.3, 95\% Cl 2.8-3.9 per 1000 live births) microcephalies were identified. Maternal hepatitis B virus carriers (HBV, OR 1.80, 95\% Cl 1.05-3.10) and primipara (OR 2.68, 95\% Cl 1.89-3.81) had higher risk of having a microcephalic baby. Higher prevalence of microcephaly was observed in women who had premature labor (OR 1.98, 95\% Cl 1.17-3.34) and had a baby with fetal growth restriction (OR 16.38, 95\% Cl 11.8122.71). Four identified factors (HBV, primiparity, preterm labor, and fetal growth restriction) contributed to $66.4 \%$ of the risk of microcephaly.

Conclusions: The prevalence of microcephaly in Guangzhou was higher than expected. This study identified four prenatal risk factors that, together, contributed to two-thirds of the increased risk of microcephaly. This is the first reported association between maternal HBV carrier status and microcephaly.
\end{abstract}

Keywords: Microcephaly, Prevalence, Risk factor, Preterm birth, Small for gestational age

\footnotetext{
* Correspondence: xiu.qiu@bigcs.org; qxiu0161@163.com

†'Songying Shen, Wanqing Xiao and Lifang Zhang contributed equally to this work.

'Division of Birth Cohort Study, Guangzhou Women and Children's Medical Center, Guangzhou Medical University, Guangzhou 510623, China

${ }^{2}$ Guangdong Provincial Key Clinical Specialty of Woman and Child Health, Guangzhou 510623, China

Full list of author information is available at the end of the article
}

(c) The Author(s). 2021 Open Access This article is licensed under a Creative Commons Attribution 4.0 International License, which permits use, sharing, adaptation, distribution and reproduction in any medium or format, as long as you give appropriate credit to the original author(s) and the source, provide a link to the Creative Commons licence, and indicate if changes were made. The images or other third party material in this article are included in the article's Creative Commons licence, unless indicated otherwise in a credit line to the material. If material is not included in the article's Creative Commons licence and your intended use is not permitted by statutory regulation or exceeds the permitted use, you will need to obtain permission directly from the copyright holder. To view a copy of this licence, visit http://creativecommons.org/licenses/by/4.0/ The Creative Commons Public Domain Dedication waiver (http://creativecommons.org/publicdomain/zero/1.0/) applies to the data made available in this article, unless otherwise stated in a credit line to the data. 


\section{Background}

Congenital microcephaly is characterized as a smaller head compared to others of the same sex and gestational age. Infants with microcephaly have a significantly increased risk of developmental delay, intellectual disability, long-term disability, and even mortality [1-5]. The World Health Organization (WHO) recommends that early intervention with multidisciplinary approaches should be used to promote the neurodevelopment of babies with microcephaly [6]. Early intervention in infants with neurodevelopmental disorders that focus on reducing problems and maximizing a child's abilities can help improve the children's quality of life [7]. An understanding of the maternal and neonatal factors related to microcephaly at birth is likely to facilitate early identification of microcephaly and thus effective intervention.

Relatively well-known causes of microcephaly include maternal infections, such as Zika virus and cytomegalovirus, genetic factors, and teratogens. These understandings are mainly based on evidence from recent Zikaepidemic areas [8-10]. The epidemiology of microcephaly in populations without an outbreak of Zika virus infection is poorly described. In addition, congenital microcephaly can be subdivided according to the proportionality related to the overall anthropometry [11, 12]. Proportionate congenital microcephaly might result from an intrauterine dystrophy [11] that impacts both head and body growth, whereas disproportionate microcephaly presents head growth lagged behind somatic growth or weight gain [12]. Case series of pregnant women with ZIKV infections have reported a disproportionate fetal growth profile [13-15], especially in those infected in early stage of pregnancy [13], the mechanism of which has been revealed by a recent animal study [16]. The proportionality of head to body size is also proposed to improve the classification and prognosis of microcephaly in clinic $[11,17,18]$. In spite of the evidence above, the epidemiology of different subtypes of microcephaly remains largely unknown.

Guangzhou, located in South China, is an area with frequent epidemics of dengue virus, which is a flavivirus of the same genus as Zika. It is possible that maternal immunity to dengue virus promotes Zika infection and Zika virus-induced microcephaly in fetuses [16]. Its natural environment is also facilitative for Zika transmission. Meanwhile, as a cosmopolitan city and an important hub port city of "the Belt and Road" in South China, Guangzhou shares frequent communications with countries where Zika virus is circulating, which may also facilitate the transmission of the disease. Evidence from Americas [19, 20] and a recent study from Angola [21] showed that prolonged local transmission of Zika virus may have existed before the detection of the outbreak, highlighting the challenge for potential risk of Zika transmission faced by South China. Improved understanding of the baseline epidemiology of microcephaly in such areas is essential to evaluate the true severity of an eventual outbreak. Using the data from a large crosssectional study in Guangzhou, China, we aimed to estimate the prevalence of, and perinatal factors related to congenital microcephaly and its subtypes.

\section{Methods}

Study design, setting and population

As head circumference (HC) measurement is not routinely collected and recorded in clinical practice in China, a surveillance study for $\mathrm{HC}$ at birth was introduced in February 2017 in four hospitals in Guangzhou, China. The four hospitals were selected using a cluster sampling from 13 municipal and district-level Maternal and Child Care Service Centers in Guangzhou, including two municipal tertiary healthcare centers (two campuses of Guangzhou Women and Children's Medical Center), one district-level tertiary centers (Huadu Maternal and Child Care Service Center) and one district-level secondary centers (Liwan Maternal and Child Care Service Center), located in the central, north and west areas of Guangzhou, China, respectively [22]. GWCMC provides services to pregnancies from all 11 districts of the city. Huadu and Liwan Maternal and Child Care Service Center mainly provide services to pregnancies from Huadu and Liwan district, respectively. The number of live births in these four study hospitals accounted for $14.1 \%$ of total live births in Guangzhou city during the study period. Singletons born at 24-42 gestational weeks between February 10th, 2017 and May 31st, 2018 were included. Stillbirths and those with a brain and central nervous system (CNS) abnormality (ICD-10 code: O35.0, Q00-Q07 excluding Q02), and/or chromosome abnormality (ICD-10 code: O351, Q90-Q99), with unknown sex, or with missing or implausible data on $\mathrm{HC}$ were excluded. The study protocol was approved by the Guangzhou Women and Children's Medical Center Ethics Approval Board (No. 2016111865-2).

\section{HC measurements and definition of microcephaly}

The $\mathrm{HC}$ of the newborns was measured at each study center by a uniform instrument, namely the Seca HC measuring band 212, made of non-stretching Teflon. The midwives were trained to follow a standard protocol before the study was started. The definition of $\mathrm{HC}$ is the widest possible circumference of the head around the back of the head with the measuring band held above eyebrow and ears. The $\mathrm{HC}$ measurements of the newborns were completed immediately after birth. All measurements were read to the nearest millimeter and then recorded. Each newborn was measured twice and the 
average value was recorded. The maximum difference accepted between the two measurements was $4 \mathrm{~mm}$.

The Z-scores of $\mathrm{HC}$ at birth was calculated according to INTERGROWTH-21st newborn size standards by gestational age and sex [23]. Microcephaly was defined as an HC Z-score at birth <- $3.0[6,11,24]$. According to the HC-to-birth weight proportionality, microcephaly was grouped into two subtypes: disproportionate microcephaly, defined as the difference between HC Z-score and birth weight Z-score (namely $\mathrm{HC}$ Z-score minus birth weight $Z$-score) $<-3.0$, which represents a head growth being lagged behind body growth by $3 \mathrm{Z}$-score when refering to the standard population; proportionate microcephaly, defined as the difference between $\mathrm{HC} \mathrm{Z}$ score and birth weight $\mathrm{Z}$-score $\geq-3.0$.

\section{Data abstraction}

Data on maternal age, parity, gestational diabetes mellitus (GDM), hypertensive disorders of pregnancy (HDP), birth weight, gestational age at delivery, and newborn sex were obtained from the Guangzhou Perinatal Health Care and Delivery Surveillance System, which covers more than 99\% of deliveries in Guangzhou [25]. GDM diagnosis was based on the International Association of Diabetes and Pregnancy Study Groups criteria (IADPSG criteria, $\mathrm{FPG} \geq 5.1 \mathrm{mmol} / \mathrm{l}, 1 \mathrm{~h}$ glucose $\geq 10.0 \mathrm{mmol} / \mathrm{l}$, and $2 \mathrm{~h}$ glucose $\geq 8.5 \mathrm{mmol} / \mathrm{l}$ ) [26]. HDP included pre-existing hypertension with or without superimposed proteinuria, gestational hypertension without significant proteinuria, preeclampsia, and eclampsia [27]. All pregnant women were screened for serum HBsAg at their first antenatal visit in GWCMC using enzyme-linked immunosorbent assay (ELISA) kits (Shanghai Kehua bio-engineering Co., Ltd., China). Maternal carrier of hepatitis B virus (HBV) was defined as positive HBs Ag. All neonates of mothers with positive $\mathrm{HBs} A g$ received hepatitis $B$ vaccine and hepatitis B immune globulin immediately after birth and hepatitis $B$ vaccine at 1 month and 6 months of age. Because an electronic medical record system is only established in GWCMC, data on maternal carriers of HBV (ICD-10 code: Z22.5) and maternal hepatitis B were only available and obtained from the electronic medical records in two GWCMC campuses through linkage to the hospital information system with a unique identifier.

Birth weight was measured by midwives immediately after delivery. Birth weight Z-scores were calculated according to INTERGROWTH-21st newborn size standards by gestational age and sex [23]. Gestational age was estimated from ultrasound examination during the first or second trimester. Fetal growth restriction (FGR) was defined as a birth weight lower than the 10th percentile for gestational age by sex. Preterm labor was defined as labor before 37 weeks of gestation.

\section{Statistical analysis}

Robust regression with the iteratively reweighted least square procedure was used to identify implausible $\mathrm{HC}$ values either caused by misclassification of gestational age or by invalid $\mathrm{HC}$ measurements. $\mathrm{HC}$ values with residual out of range of -3.89 SD and + 3.89 SD were considered as outliers $[28,29]$.

The prevalence of microcephaly and its subtypes was estimated and the $95 \% \mathrm{CI}$ was calculated using the binomial exact method. Data were summarized as means (standard deviations) for continuous variables and frequency (percentage) for categorical variables.

Multivariable logistic regression models were applied to estimate the unadjusted and adjusted odds ratios (ORs) and 95\% confidence intervals (CIs) for the association between prenatal characteristics and the risk of microcephaly or microcephaly subtypes, with nonmicrocephaly (HC Z-score at birth $\geq-3.0$ ) as the reference. In models for the associations with maternal age, GDM, HDP, and parity, these characteristics entered the model simultaneously and were mutually adjusted for each other. The association with maternal carrier of HBV was assessed among births in GWCMC, adjusted for maternal age at conception, parity, HDP, GDM, year of birth, and place of birth. Based on the year when routine hepatitis B immunization for newborns was implemented, the year of birth was grouped into a binary variable ("before 1992" and "in 1992 or after") [30, 31]. Maternal place of birth was classified into two regions according the distribution of HBV infection, including the eastern region (including Beijing, Fujian, Guangdong, Jiangsu, Liaoning, Shandong, Shanghai, Tianjin, and Zhejiang) and the central/western region (including Anhui, Hainan, Hebei, Heilongjiang, Henan, Hubei, Hunan, Jiangxi, Jilin, Shanxi, Chongqing, Gansu, Guangxi, Guizhou, Inner Mongolia, Ningxia, Qinghai, Shaanxi, Sichuan, Tibet, Yunnan, and Xinjiang) [32]. In the models to examine the association of microcephaly with preterm labor and FGR, maternal age, parity, HDP, GDM, and infant's sex were adjusted for. We calculated the population attributable fraction (PAF) and its 95\% confidence interval associated with identified factors for the risk of microcephaly and its subtypes in the study population, using a published \%PAR SAS macro [33].

All analyses were done with SAS version 9.3 (SAS Institute, Cary, NC, USA). $P<0.05$ was considered significant.

\section{Results}

A total of 47,369 singletons were eligible, with 17,798 births from Zhujiang Newtown Campus of GWCMC, 12,270 births from Maternal-Infant Campus of GWCM C, 13,217 from Guangzhou Huadu Maternal and Child Care Service Center, and 4084 from Guangzhou Liwan 
Maternal and Child Care Service Center. After excluding newborns with unknown sex $(n=3)$ and missing $(n=$ $328)$ or implausible HC data $(n=145)$, stillbirths $(n=$ 222 ), and those with brain and central nervous system (CNS) abnormalities $(n=25)$ and/or chromosome abnormalities $(n=36), 46,610$ newborns were included in the final analysis.

There were 154 newborns identified with microcephaly across all births, with a prevalence of 3.3 (95\% CI, 2.8-3.9 per 1000 live births). Of these, 14 were disproportionate, with a prevalence of 0.3 ( $95 \% \mathrm{CI}, 0.2-0.5$ per 1000 live births), and the remaining 140 were proportionate, with a prevalence of $3(95 \%$ CI, $2.5-3.5$ per 1000 live births).

Table 1 shows the characteristics of the study population. There were $83.7 \%(39,019 / 46,610)$ of mothers who were less than 35 years of age. The proportion of mothers who were primiparous was $41.9 \%(19,534 / 46$, $610)$. There were $3.2 \%(1493 / 46,610)$ and $14.6 \%$ (6787/ 46,610 ) of mothers diagnosed with HDP and GDM, respectively. A total of $7.5 \%(2189 / 29,187)$ of mothers were carriers of HBV, of whom only 9 were diagnosed with hepatitis B. The proportions of preterm labor and FGR were 5.6 and $7.0 \%$, respectively. Male accounted for $53.5 \%(n=24,927)$ of the newborns. The mean HC Z score, birth weight $\mathrm{Z}$ score and difference between the $\mathrm{HC}$ Z-score and birth weight Z-score were-0.3 (SD 1.0), 0.0 (SD 0.9), and $0.3(0.8)$, respectively.

Associations between prenatal factors and microcephaly are shown in Fig. 1. Being a maternal carrier of HBV (adjusted OR 1.80; 95\% CI, 1.05-3.10) and primiparity (adjusted OR $2.68 ; 95 \%$ CI, 1.89-3.81) were significantly associated with microcephaly. There was no association of microcephaly with maternal age, GDM, or HDP. Higher microcephaly risk was associated with preterm birth (OR 1.98; 95\% CI, 1.17-3.34), SGA (OR 16.38; 95\% CI, 11.81-22.71).

Associations between prenatal factors and microcephaly subtypes are shown in Table 2. Newborns had a higher risk of proportionate microcephaly if they were SGA (adjusted OR 20.76, 95\% CI 14.61-29.51) or if their mothers were primiparous (adjusted OR 2.83, 95\% CI 1.95-4.10) or had HDP (adjusted OR 2.06, 95\% CI 1.044.07). Newborns who were born preterm (adjusted OR 14.24, 95\% CI 4.91-41.30) had a higher risk of disproportionate microcephaly. Maternal HBV carrier status was not significantly associated with either proportionate (adjusted OR 1.73 95\% CI 0.97-3.09) or disproportionate (adjusted OR 2.51, 95\% CI 0.55-11.53) microcephaly.

The PAF associated with identified risk factors for microcephaly and its subtypes are presented in Table 3.

Table 1 Characteristics of 46,610 mother-child dyads

\begin{tabular}{|c|c|c|}
\hline Characteristics & Mean (SD) & n (\%) \\
\hline Maternal age & $30.2(4.7)$ & \\
\hline$<35$ years old & & $39,019(83.7)$ \\
\hline Primiparous & & $19,534(41.9)$ \\
\hline Hypertensive disorders of pregnancy & & $1493(3.2)$ \\
\hline Gestational diabetes & & $6787(14.6)$ \\
\hline Maternal carrier of $\mathrm{HBV}^{\mathrm{a}}$ & & $2189(7.5)$ \\
\hline Sex of newborns (Male) & & $24,927(53.5)$ \\
\hline Gestational age at birth, weeks & $39.0(1.5)$ & \\
\hline Preterm birth & & $2590(5.6)$ \\
\hline Birth weight of newborns, kg & $3.2(0.4)$ & \\
\hline Birth weight for gestational age of newborns, Z-score ${ }^{b}$ & $0.0(0.9)$ & \\
\hline Small for gestational age ${ }^{c}$ & & $3265(7.0)$ \\
\hline Head circumference of newborns, $\mathrm{cm}$ & $33.3(1.3)$ & \\
\hline Head circumference of newborns, Z-score ${ }^{b}$ & $-0.3(1.0)$ & \\
\hline$<-3.0$ & & $154(0.3)$ \\
\hline$\geq-3.0 \&<-2.0$ & & $1777(3.8)$ \\
\hline BWHC Z-score difference ${ }^{d}$ & $-0.3(0.8)$ & \\
\hline$<-3.0$ & & $58(0.1)$ \\
\hline$\geq-3.0 \&<-2.0$ & & $987(2.1)$ \\
\hline
\end{tabular}

HBV Hepatitis B Virus, SD Standard deviation, BWHC Birth weight and head circumference of newborns

${ }^{a}$ Analyzed among the births born in two campuses of Guangzhou Women and Children's Medical Center $(n=29,493)$

${ }^{b}$ Calculated according to the INTERGROWTH-21st standards

'Defined as gestational age and sex-adjusted birth weight $<10$ th percentile based on the INTERGROWTH-21st newborn size standard

${ }^{\mathrm{d} D e f i n e d}$ as the difference between head circumference Z-score and birth weight Z-score of newborns 


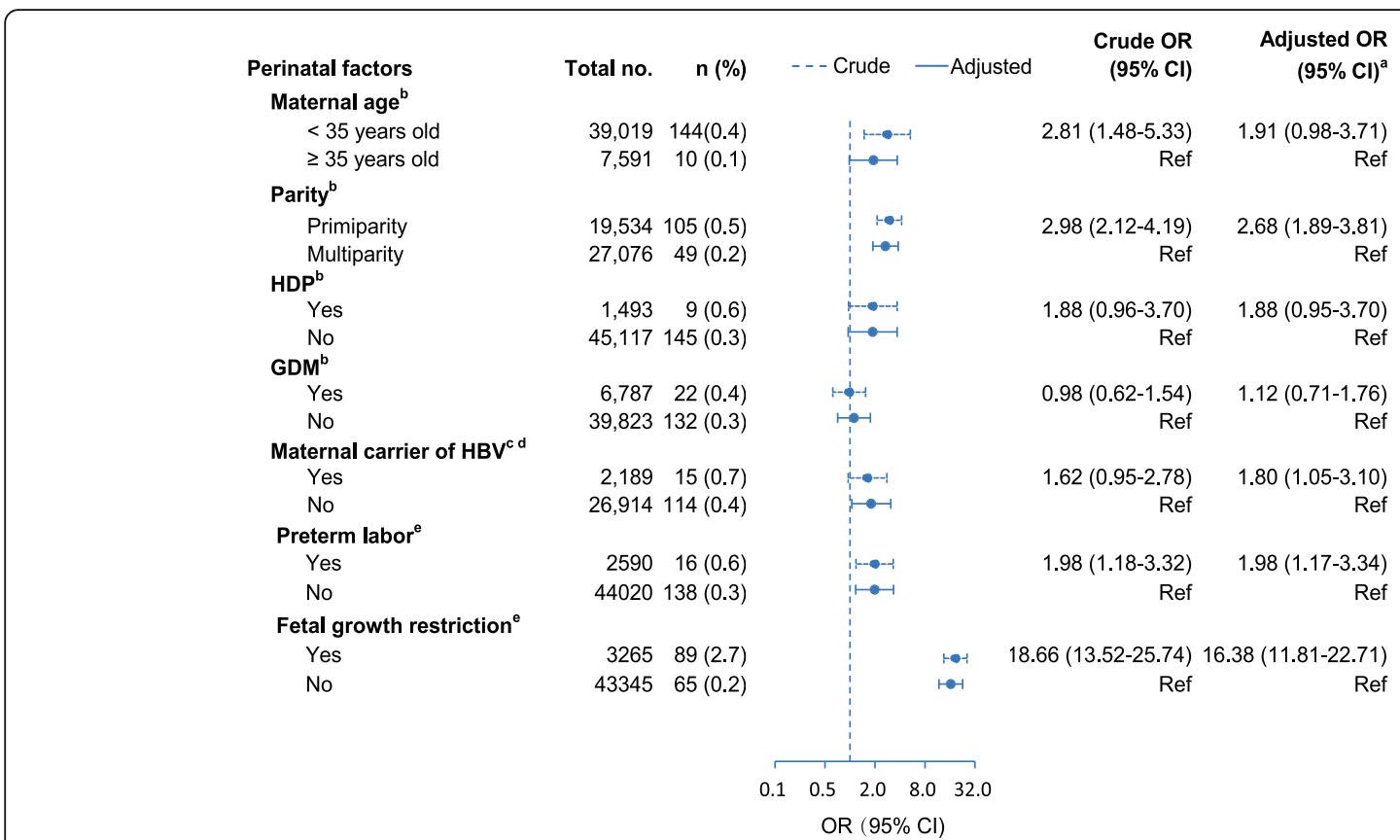

Fig. 1 Pernatal factors associated with microcephaly. OR, odds ratio; HDP, hypertensive disorders of pregnancy; GDM, Gestational diabetes

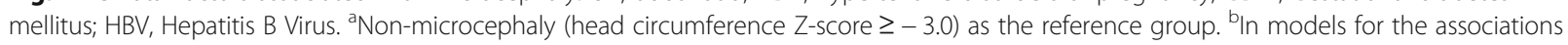
with maternal age, GDM, HDP, and parity, these characteristics entered the model simultaneously and were mutually adjusted for each other. cAnalyzed only among all births born in two campuses of Guangzhou Women and Children's Medical Center. ${ }^{\mathrm{d}}$ Adjusted for maternal age,

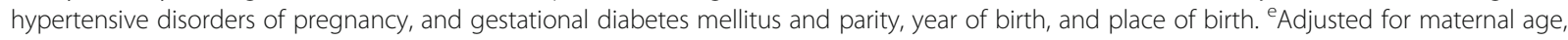
hypertensive disorders of pregnancy, and gestational diabetes mellitus, parity and sex of newborn.

In the study population, $66.4 \%$ (95\% CI $43.9-81.1 \%)$ of the risk of microcephaly could be attributed to the four associated risk factors, including primiparity, maternal HBV carriage status, SGA, and preterm birth. The most important factors were SGA and primiparity, with PAF being 50.6\% (95\% CI 38.8-60.8\%) and 28.9\% (95\% CI 10.3-45.5\%), respectively. For disproportionate microcephaly, the PAF associated with preterm birth was $47.5 \%$ (95\% CI 13.1-71.7\%). For proportionate microcephaly, $56.5,28.2$, and $1.9 \%$ of the risk could be attributed to SGA, primiparity, and HDP, respectively, constituting a combined PAF of $67.7 \%$ (95\% CI $47.7-$ $81.1 \%)$.

\section{Discussion}

This multi-center study found that the prevalence of microcephaly was $0.33 \%$, which is higher than the expected risk of $0.13 \%$ in a population with normally distributed $\mathrm{HC}$ and using a definition of $\mathrm{HC} \mathrm{Z}$ score smaller than - 3. Microcephaly was associated with maternal HBV carrier status, primiparity, FGR, and preterm birth, which together contributed to two-thirds of the risk of microcephaly. The risk factors associated with microcephaly varied between proportionate and disproportionate microcephaly.
Although the estimated prevalence of microcephaly in the present study is lower than pre-Zika virus epidemic estimate in two cities in Brazil (5 7 per 1000 births), where the diagnosis of microcephaly was also based on the INTERGROWTH-21st standard [34], it was $\sim 2$ folds higher than the expected rate (1.3 per 1000 births). The rate is also much higher than that from birth defect surveillance systems in other regions of the world, which were reported as 0.20 per 1000 births in Europe, 0.23 per 1000 births in India, 0.44 per 1000 births in South America pre-Zika, and around 0.87 per 1000 live births before the Zika virus epidemic in the US [17, 35-37]. The variation in the definition of microcephaly used is likely to contribute largely to the variation in the reported prevalence across the studies mentioned. Nevertheless, this study showed that microcephaly is subendemic in a region without ongoing Zika virus transmission.

Considering that early neurodevelopmental interventions recommended by the World Health Organization could improve microcephalic children's quality of life [6], identification of risk factors and comorbidities for microcephaly and its subtypes may allow for timely diagnoses and enable clinical practitioners to provide appropriate counseling about the long-term prognosis. The present study adds to the evidence that risk factors 
Table 2 Perinatal factors associated with microcephaly phenotypes

\begin{tabular}{|c|c|c|c|c|}
\hline \multirow{2}{*}{$\begin{array}{l}\text { Perinatal } \\
\text { factors }\end{array}$} & \multicolumn{2}{|c|}{ Disproportionate microcephaly } & \multicolumn{2}{|c|}{ Proportionate microcephaly } \\
\hline & n (\%) & $\overline{\text { Adjusted OR }(95 \% \mathrm{Cl})^{\mathrm{a}}}$ & n (\%) & Adjusted OR $(95 \% \mathrm{Cl})^{\mathrm{a}}$ \\
\hline \multicolumn{5}{|l|}{ Maternal age ${ }^{b}$} \\
\hline$<35$ years old & $13(0.03)$ & $1.90(0.23-15.42)$ & $131(0.34)$ & $1.91(0.95-3.85)$ \\
\hline$\geq 35$ years old & $1(0.01)$ & Ref & $9(0.12)$ & Ref \\
\hline \multicolumn{5}{|l|}{ Parity $^{b}$} \\
\hline Primiparity & $8(0.04)$ & $1.64(0.55-4.87)$ & $97(0.50)$ & $2.83(1.95-4.10)$ \\
\hline Multiparity & $6(0.02)$ & Ref & $43(0.16)$ & Ref \\
\hline \multicolumn{5}{|l|}{$\mathrm{HDP}^{\mathrm{b}}$} \\
\hline Yes & $0(0.00)$ & - & $9(0.60)$ & $2.06(1.04-4.07)$ \\
\hline No & $14(0.03)$ & - & $131(0.29)$ & Ref \\
\hline \multicolumn{5}{|l|}{$\mathrm{GDM}^{\mathrm{b}}$} \\
\hline Yes & $1(0.01)$ & $0.52(0.07-4.04)$ & $21(0.31)$ & $1.18(0.74-1.89)$ \\
\hline No & $13(0.03)$ & Ref & $119(0.30)$ & Ref \\
\hline \multicolumn{5}{|c|}{ Maternal carrier of $\mathrm{HBV}^{c, d}$} \\
\hline Yes & $2(0.09)$ & $2.51(0.55-11.53)$ & $13(0.59)$ & $1.73(0.97-3.09)$ \\
\hline No & $10(0.04)$ & Ref & $104(0.39)$ & Ref \\
\hline \multicolumn{5}{|l|}{ Preterm birth ${ }^{e}$} \\
\hline Yes & $6(0.23)$ & $14.24(4.91-41.30)$ & $10(0.39)$ & $1.29(0.68-2.47)$ \\
\hline No & $8(0.02)$ & Ref & $130(0.30)$ & Ref \\
\hline \multicolumn{5}{|c|}{ Small for gestational age $\mathrm{e}^{\mathrm{e}}$} \\
\hline Yes & $0(0.00)$ & - & $89(2.73)$ & $20.76(14.61-29.51)$ \\
\hline No & $14(0.03)$ & - & $51(0.12)$ & Ref \\
\hline
\end{tabular}

OR Odds ratio, CI Confidence interval, HDP Hypertensive disorders of pregnancy, GDM Gestational diabetes mellitus, HBV Hepatitis B Virus

${ }^{a}$ Non-microcephaly (head circumference $Z$-score $\geq-3.0$ ) as the reference group

${ }^{\mathrm{b}}$ In models for the associations with maternal age, GDM, HDP, and parity, these characteristics entered the model simultaneously and were mutually adjusted for each other

'Analyzed only among all births born in two campuses of Guangzhou Women and Children's Medical Center

${ }^{\mathrm{d}}$ Adjusted for maternal age, hypertensive disorders of pregnancy, and gestational diabetes mellitus and parity, year of birth, and place of birth

${ }^{\mathrm{e}}$ Adjusted for maternal age, hypertensive disorders of pregnancy, gestational diabetes mellitus, and parity, sex of newborn

associated with microcephaly varied between two subtypes, proportionate and disproportionate, of microcephaly.

In the present study, we found that infants with proportionate microcephaly included more infants with SGA, $18-22 \%$ of whom were reported constitutionally small but healthy in the previous studies [38]. As the definition of microcephaly was only based on head circumference rather than aetiological investigations, it is inevitable that infants with proportionate microcephaly include some SGA infants whose head sizes are small but without structural brain lesion [39].

Table 3 Population attributable fractions and 95\% confidence interval associated with identified factors for microcephaly and its subtypes

\begin{tabular}{llll}
\hline Risk factors & Microcephaly & Disproportionate microcephaly & Proportionate microcephaly \\
\hline $\begin{array}{l}\text { All risk factors combined } \\
\text { Specific factors }\end{array}$ & $66.4 \%(43.9-81.1 \%)$ & $47.5 \%(13.1-71.7 \%)$ & $67.7 \%(47.7-81.1 \%)$ \\
$\quad$ Primiparity & $28.9 \%(10.3-45.5 \%)$ & - & $28.2 \%(7.9-46.3 \%)$ \\
HDP & - & - & $1.9 \%(-3.2$ to 6.9\%) \\
Maternal carrier of HBV & $4.8 \%(-1.2$ to $10.8 \%)$ & - & - \\
Small for gestational age & $50.6 \%(38.8-60.8 \%)$ & - & $56.5 \%(44.0-66.9 \%)$ \\
Preterm birth & $4.0 \%(-1.4$ to $9.4 \%)$ & $47.5 \%(13.1-71.7 \%)$ & - \\
\hline
\end{tabular}

HDP Hypertensive disorders of pregnancy, HBV Hepatitis B Virus 
The definition of disproportionate microcephaly in the present study represents a head growth being significantly lagged behind body growth. Previous studies defined disproportionate microcephaly as $\mathrm{HC} \mathrm{Z}$-score $<-3$ and weight or height Z-score $\geq-3$, which will include a large portion of infants whose head growth being little lagged behind body growth [12, 34]. It is intriguing to find that disproportionate microcephaly is associated with preterm labor, especially as preterm labor has itself been linked to neurodevelopmental delays [40-43]. On one hand, the finding may suggest that factors contributing to preterm labor might also have an impact on those related to the pathogenesis of microcephaly, such as neural progenitor cell proliferation, differentiation, and apoptosis [8]. Further studies are warranted for identifying these factors. On the other hand, the disruption of the normal intrauterine neurodevelopment, a critical period for brain growth and maturation, would further exacerbate the neurodevelopmental disorders of the children $[40,43]$. Thus, disproportionate microcephaly may have a greater chance of representing 'true' microcephaly. Identification of disproportionate microcephaly in preterm babies and referring them to early intervention services to improve neurodevelopmental outcomes would be urgently needed.

This study is the first to report the association between maternal HBV carrier status and a higher risk of microcephaly. Previous studies regarding maternal virus infection and microcephaly focused mainly on the Zika virus and were conducted mainly in Zika-epidemic areas. Some previous studies have found that Hepatitis B surface antigen ( $\mathrm{HBsAg}$ ) positivity during pregnancy increased the risk of congenital malformation [44]. However, few studies have investigated the influence of maternal HBsAg positivity on fetal brain growth. As TORCH (Toxoplasma gondii, other microorganisms, rubella virus, cytomegalovirus, and herpes simplex virus) infections are one of the main causes of microcephaly, future studies are needed to confirm this association and determine the public health impact of maternal HBV infection on the risk of microcephaly in regions with high HBV infection burden, such as in China and Africa [45].

Major strengths of this study include the large sample size, which allows for the identification of novel risk factors of conditions with low prevalence, and the highquality of $\mathrm{HC}$ data that was ensured by standardized measurements. Importantly, using high quality data we provide approximate population-based baseline prevalence estimations for future surveillance, which will become very important in the case of outbreaks of Zika or other infectious diseases in this region of China. This study has some limitations. First, we only collected the data in one developed city in China, which limits its generalization to other regions. However, Guangzhou is a megalopolis with a large migrating population moving in from other areas of China. Second, the association between $\mathrm{HBV}$ and microcephaly should be interpreted with caution because potential unrecognized confounders within populations with higher hepatitis B rates may drive this association. However, in a subgroup of pregnant women who participated in both the current study and the Born in Guangzhou Cohort Study [46], the ORs changed very little after additional adjustment for known influential factors, such as alcohol consumption, smoking, and use of emergency contraceptives during early pregnancy (data not shown). This suggests that the observed associations are unlikely to be largely changed by adjustment for known confounders. Third, the power to detect the associations between risk factors and disproportionate microcephaly might be limited due to the small sample size of this subgroup. Finally, only microcephaly-status and comorbidities at birth were observed. Long-term neurodevelopmental and other outcomes of infants with microcephaly, according to subtype, at birth should be further evaluated in future studies in order to better understand the clinical significance of finding microcephaly without other brain abnormalities at birth.

\section{Conclusions}

In summary, based on this multi-center study in an area not yet experiencing, but at risk of, Zika outbreaks, the estimated prevalence of microcephaly was higher than expected. Four factors, namely maternal HBV carrier status, primiparity, SGA, and preterm birth, are associated with $66.4 \%$ of the increased risk of microcephaly, and the risk factors varied between different subtypes of microcephaly. This study contributed to the better understanding of microcephaly subtypes characteristics. In addition, as infection is a main cause of microcephaly, the association between maternal HBV carrier status and microcephaly, which was first reported in this study, warrants further investigations.

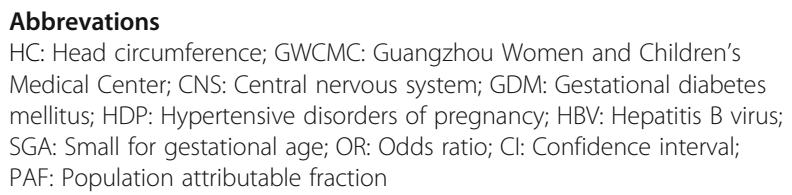

\section{Acknowledgments}

The authors thank all participants in the study; Huizhu Zhang, Shunping $\mathrm{Hu}$, Ruoya Yang and Guiyou Li who coordinated the data collection in the study centers.

\section{Authors' contributions}

XQ conceived the study. XQ, SS, WX, LZ designed and directed the study. SS, $W X$ and $L Z$ drafted the manuscript. WX, LZ and $J L$ cleaned and analyzed the data. WX, AF (Funk), JH, ST, JY and LY were involved in data acquisition and data management. $\mathrm{XQ}, \mathrm{AF}$ (Fontanet), WB and KKC interpreted the data and revised the manuscript. All authors have approved the final article. 


\section{Funding}

This work was supported by Ministry of Science and Technology of People's Republic of China [grant number 2016YFC1000304]; National Natural Science Foundation of China [grant numbers 81673181, 81803251, 81703244]; Department of Science and Technology of Guangdong Province, China [grant numbers 2019B030301004, 2019B020227001, 2019B030316014], and Laboratoire d'Excellence Integrative Biology of Emerging Infectious Diseases programme [grant number ANR-10-LABX-62-IBEID]. The funding sources had no involvement in the study design, the collection, analysis, and interpretation of data, the writing of the report, and the decision to submit the paper for publication.

\section{Availability of data and materials}

The data that support the findings of this study are not shared due to national and regional data regulation policy.

\section{Declarations}

\section{Ethics approval and consent to participate}

The study was approved by the Guangzhou Women and Children's Medical Center Ethics Approval Board (No. 2016111865-2). All data were collected as part of routine practice and de-identified. According to statement from the National and Local Ethical Review Board, informed consent was not needed.

\section{Consent for publication}

Not applicable.

\section{Competing interests}

The authors declare that they have no competing interests.

\section{Author details}

'Division of Birth Cohort Study, Guangzhou Women and Children's Medical Center, Guangzhou Medical University, Guangzhou 510623, China. ${ }^{2}$ Guangdong Provincial Key Clinical Specialty of Woman and Child Health, Guangzhou 510623, China. ${ }^{3}$ Department of Pediatrics, University of Calgary, Calgary T2N 1N4, Canada. ${ }^{4}$ Emerging Disease Epidemiology Unit, Institut Pasteur, 75015 Paris, France. ${ }^{5}$ Department of Epidemiology, College of Public Health, University of lowa, lowa City, lowa 52242, USA. ${ }^{6}$ Institute of Applied Health Research, College of Medical and Dental Sciences, University of Birmingham, B15 2TT, Birmingham, UK. Guangdong Provincial Clinical Research Center for Child Health, Guangzhou 510623, China.

\section{Received: 11 September 2020 Accepted: 10 March 2021}

\section{Published online: 17 March 2021}

\section{References}

1. Gordon-Lipkin E, Gentner MB, German R, Leppert ML. Neurodevelopmental outcomes in 22 children with microcephaly of different etiologies. J Child Neurol. 2017;9:804-9.

2. Satterfield-Nash A, Kotzky K, Allen J, Bertolli J, Moore CA, Pereira IO, et al. Health and development at age 19-24 months of 19 children who were born with microcephaly and laboratory evidence of congenital Zika virus infection during the 2015 Zika virus outbreak - Brazil, 2017. MMWR Morb Mortal Wkly Rep. 2017;49:1347-51.

3. Moura da Silva AA, Ganz JS, Sousa PD, Doriqui MJ, Ribeiro MR, Branco MD, et al. Early growth and neurologic outcomes of infants with probable congenital Zika virus syndrome. Emerg Infect Dis. 2016;11:1953-6.

4. Ashwal S, Michelson D, Plawner L, Dobyns WB. Practice parameter: evaluation of the child with microcephaly (an evidence-based review): report of the quality standards Subcommittee of the American Academy of neurology and the practice Committee of the Child Neurology Society. Neurology. 2009;11:887-97.

5. Aagaard K, Bach CC, Henriksen TB, Larsen RT, Matthiesen NB. Head circumference at birth and childhood developmental disorders in a nationwide cohort in Denmark. Paediatr Perinat Epidemiol. 2018;5:458-66.

6. World Health Organization. Screening, assessment and management of neonates and infants with complications associated with Zika virus exposure in utero. http://apps.who.int/iris/bitstream/handle/10665/204475/ WHO_ZIKV_MOC_16.3_eng.pdf. Accessed July 20, 2018.
7. Cioni G, Inguaggiato $E$, Sgandurra G. Early intervention in neurodevelopmental disorders: underlying neural mechanisms. Dev Med Child Neurol. 2016;4:61-6.

8. Devakumar D, Bamford A, Ferreira MU, Broad J, Rosch RE, Groce N, et al. Infectious causes of microcephaly: epidemiology, pathogenesis, diagnosis, and management. Lancet Infect Dis. 2018;1:e1-e13.

9. Auger N, Quach C, Healy-Profitos J, Lowe AM, Arbour L. Congenital microcephaly in Quebec: baseline prevalence, risk factors and outcomes in a large cohort of neonates. Arch Dis Child Fetal Neonatal Ed. 2018;2:F167F72.

10. Olusanya BO. Full-term newborns with congenital microcephaly and macrocephaly in Southwest Nigeria. Int Health. 2012;2:128-34.

11. von der Hagen M, Pivarcsi M, Liebe J, von Bernuth H, Didonato N, Hennermann JB, et al. Diagnostic approach to microcephaly in childhood: a two-center study and review of the literature. Dev Med Child Neurol. 2014; 8:732-41.

12. de Magalhaes-Barbosa MC, Prata-Barbosa A, Robaina JR, Raymundo CE, Lima-Setta F, da Cunha AJLA. Prevalence of microcephaly in eight southeastern and midwestern Brazilian neonatal intensive care units: 2011-2015. Arch Dis Child. 2017;8:728-34.

13. Brasil P, Pereira JP Jr, Moreira ME, Ribeiro Nogueira RM, Damasceno L, Wakimoto $\mathrm{M}$, et al. Zika virus infection in pregnant women in Rio de Janeiro. N Engl J Med. 2016;24:2321-34.

14. Sohan K, Cyrus CA. Ultrasonographic observations of the fetal brain in the first 100 pregnant women with Zika virus infection in Trinidad and Tobago. Int J Gynaecol Obstet. 2017;3:278-83.

15. Oliveira Melo AS, Malinger G, Ximenes R, Szejnfeld PO, Alves Sampaio S, Bispo de Filippis AM. Zika virus intrauterine infection causes fetal brain abnormality and microcephaly: tip of the iceberg? Ultrasound Obstet Gynecol. 2016;1:6-7.

16. Rathore APS, Saron WAA, Lim T, Jahan N, St John AL. Maternal immunity and antibodies to dengue virus promote infection and Zika virus-induced microcephaly in fetuses. Sci Adv. 2019;2:eaav3208.

17. Orioli IM, Dolk H, Lopez-Camelo JS, Mattos D, Poletta FA, Dutra MG, et al. Prevalence and clinical profile of microcephaly in South America pre-Zika, 2005-14: prevalence and case-control study. BMJ. 2017;359:55018.

18. Hofman MA. A biometric analysis of brain size in micrencephalics. J Neurol. 1984;2:87-93.

19. Grubaugh ND, Faria NR, Andersen KG, Pybus OG. Genomic insights into Zika virus emergence and spread. Cell. 2018;6:1160-2.

20. Grubaugh ND, Ladner JT, Kraemer MUG, Dudas G, Tan AL, Gangavarapu K, et al. Genomic epidemiology reveals multiple introductions of Zika virus into the United States. Nature. 2017;7658:401-5.

21. Hill SC, Vasconcelos J, Neto Z, Jandondo D, Ze-Ze L, Aguiar RS, et al. Emergence of the Asian lineage of Zika virus in Angola: an outbreak investigation. Lancet Infect Dis. 2019;10:1138-47.

22. Xiao WQ, Zhang LF, He JR, Shen SY, Funk AL, Lu JH, et al. Comparison of the INTERGROWTH-21st standard and a new reference for head circumference at birth among newborns in southern China. Pediatr Res. 2019;4:529-36.

23. Villar J, Cheikh Ismail L, Victora CG, Ohuma EO, Bertino E, Altman DG, et al. International standards for newborn weight, length, and head circumference by gestational age and sex: the newborn cross-sectional study of the INTERGROWTH-21st project. Lancet. 2014;9946:857-68.

24. Woods CG. Human microcephaly. Curr Opin Neurobiol. 2004;1:112-7.

25. He JR, Liu Y, Xia XY, Ma WJ, Lin HL, Kan HD, et al. Ambient temperature and the risk of preterm birth in Guangzhou, China (2001-2011). Environ Health Perspect. 2016;7:1100-6.

26. Metzger BE, Gabbe SG, Persson B, Buchanan TA, Catalano PA, Damm P, et al. International association of diabetes and pregnancy study groups recommendations on the diagnosis and classification of hyperglycemia in pregnancy. Diabetes Care. 2010;3:676-82.

27. Obstetrics Subgroup Group of Pregnancy with Hypertensive Disorders of Pregnancy, Chinese Society of Obstetrics and Gynecology, Chinese Medical Association. Guidelines for the management of hypertensive disorders of pregnancy. Chinese J Obstetr Gynecol. 2015;50:721-8.

28. He JR, Xia HM, Liu Y, Xia XY, Mo WJ, Wang P, et al. A new birthweight reference in Guangzhou, southern China, and its comparison with the global reference. Arch Dis Child. 2014;12:1091-7.

29. Kecojević T, Foster PJ. Advances in social science research using R. New York: Springer; 2010. 
30. Liang X, Bi S, Yang W, Wang L, Cui G, Cui F, et al. Evaluation of the impact of hepatitis B vaccination among children born during 1992-2005 in China. J Infect Dis. 2009;1:39-47.

31. Yan YP, Su HX, Ji ZH, Shao ZJ, Pu ZS. Epidemiology of hepatitis B virus infection in China: current status and challenges. J Clin Transl Hepatol. 2014; 1:15-22.

32. Wang $Y$, Zhou H, Zhang L, Zhong $Q$, Wang $Q$, Shen $H$, et al. Prevalence of chronic hepatitis $B$ and status of HBV care among rural women who planned to conceive in China. Sci Rep. 2017;1:12090.

33. Spiegelman D, Hertzmark E, Wand HC. Point and interval estimates of partial population attributable risks in cohort studies: examples and software. Cancer Causes Control. 2007;5:571-9.

34. Silva AA, Barbieri MA, Alves MT, Carvalho CA, Batista RF, Ribeiro MR, et al. Prevalence and risk factors for microcephaly at birth in Brazil in 2010. Pediatrics. 2018:2:e20170589.

35. Morris JK, Rankin J, Garne E, Loane M, Greenlees R, Addor MC, et al. Prevalence of microcephaly in Europe: population based study. BMJ. 2016: 354:14721.

36. Cragan JD, Isenburg JL, Parker SE, Alverson CJ, Meyer RE, Stallings EB, et al. Population-based microcephaly surveillance in the United States, 2009 to 2013: an analysis of potential sources of variation. Birth Defects Res A Clin Mol Teratol. 2016;11:972-82.

37. Bhidea P, Kara A. Birth prevalence of microcephaly in India: Bulletin of the World Health Organization; 2016.

38. McCowan LM, Figueras F, Anderson NH. Evidence-based national guidelines for the management of suspected fetal growth restriction: comparison, consensus, and controversy. Am J Obstet Gynecol. 2018;2S:S855-S68.

39. Longo S, Borghesi A, Tzialla C, Stronati M. IUGR and infections. Early Hum Dev. 2014;1:S42-4.

40. Cheong JL, Doyle LW, Burnett AC, Lee K, Walsh JM, Potter CR, et al. Association between moderate and late preterm birth and neurodevelopment and social-emotional development at age 2 years. JAMA Pediatr. 2017:4:e164805.

41. Luu TM, Rehman Mian MO, Nuyt AM. Long-term impact of preterm birth: neurodevelopmental and physical health outcomes. Clin Perinatol. 2017;2 $305-14$

42. Katz J, Lee AC, Kozuki N, Lawn JE, Cousens S, Blencowe H, et al. Mortality risk in preterm and small-for-gestational-age infants in low-income and middle-income countries: a pooled country analysis. Lancet. 2013;9890:417-25.

43. Moore T, Hennessy EM, Myles J, Johnson SJ, Draper ES, Costeloe KL, et al. Neurological and developmental outcome in extremely preterm children born in England in 1995 and 2006: the EPICure studies. BMJ. 2012;345: e7961.

44. Tan J, Huang S, He G, Tang L, Ren Y, Zheng J, et al. Maternal hepatitis B surface antigen carrier status and its impact on neonatal outcomes: a cohort study of 21947 singleton newborns in China. J Matern Fetal Neonatal Med. 2017;18:2219-24.

45. Seto WK, Lo YR, Pawlotsky JM, Yuen MF. Chronic hepatitis B virus infection. Lancet. 2018;10161:2313-24.

46. Qiu X, Lu JH, He JR, Lam KH, Shen SY, Guo Y, et al. The born in Guangzhou cohort study (BIGCS). Eur J Epidemiol. 2017;4:337-46.

\section{Publisher's Note}

Springer Nature remains neutral with regard to jurisdictional claims in published maps and institutional affiliations.

Ready to submit your research? Choose BMC and benefit from:

- fast, convenient online submission

- thorough peer review by experienced researchers in your field

- rapid publication on acceptance

- support for research data, including large and complex data types

- gold Open Access which fosters wider collaboration and increased citations

- maximum visibility for your research: over $100 \mathrm{M}$ website views per year

At $\mathrm{BMC}$, research is always in progress.

Learn more biomedcentral.com/submissions 